\title{
CONFIGURAÇÕES DE IDENTIDADES ÉTNICAS EM ASSOCIAÇÕES ESPORTIVAS: PRÁTICAS E REPRESENTAÇÕES CULTURAIS
}

\author{
CONFIGURATIONS OF ETHNIC IDENTITIES IN SPORTS ASSOCIATIONS: \\ CULTURAL REPRESENTATIONS AND PRACTICES
}

\author{
CONFIGURACIONES DE IDENTIDADES ÉTNICAS EN ASOCIACIONES \\ DEPORTIVAS: PRÁCTICAS Y REPRESENTACIONES CULTURALES
}

\author{
Alice Beatriz Assmann*, Janice Zarpellon Mazo*
}

Palavras chave: Grupos étnicos. História.

Esportes.

Migração.

Keywords Ethnic groups. History.

Sports. Migration.

Palabras clave: Grupos étnicos. Historia. Deportes. Migración.
Resumo: A presente pesquisa investiga como as associaç̃os esportivas de tiro ao alvo e cavalaria de Santa Cruz do Sul se configuraram em espaços de representações de identidades étnicas, entre o final do século XIX e começo do XX. As fontes impressas analisadas evidenciaram que os atiradores e cavaleiros afirmavam e reconfiguravam representações de identidades teuto-brasileiras através das associações esportivas, de forma plural e fluida, em uma relação dinâmica com o espaço sociocultural.

Abstract: This study investigates how the sports associations of target shooting and horse riding from Santa Cruz do Sul became spaces for ethnic identity representations between the late $19^{\text {th }}$ and early $20^{\text {th }}$ century. The printed sources analyzed revealed that shooters and riders affirm and reconfigured representations of German-Brazilian identities through sports associations in a plural and fluid way, in a dynamic relation with the sociocultural space.

Resumen: Este estudio investiga cómo las asociaciones deportivas de tiro al blanco y caballería de Santa Cruz do Sul se configuraron en espacios de representaciones de identidades étnicas, entre fines del siglo XIX y principios del XX. Las fuentes impresas analizadas mostraron que los tiradores deportivos y los caballeros afirmaban y reconfiguraban representaciones de identidades germano-brasileñas a través de las asociaciones deportivas, de forma plural y fluida, en una relación dinámica con el espacio sociocultural.
*Universidade Federal do Rio Grande do Sul. Porto Alegre, RS, Brasil. E-mail: alice.assmann@gmail.com; janice.mazo@ufrgs.br

Recebido em: 19-10-2016 Aprovado em: 08-03-2017

\section{(c) (i) (9) Licence}




\section{INTRODUÇÃOO}

As associações esportivas que emergiram a partir de meados do século XIX em Santa Cruz do Sul foram espaços significativos na vida social e cultural desta que foi a primeira colônia alemã pública do estado do Rio Grande do Sul. Seyferth (2000) afirma que o termo "colônia alemã" indica uma especificidade linguística, uma organização comunitária e estilo de vida específicos, associados à localização de imigrantes de uma mesma origem nacional em determinadas áreas. Essas especificidades fomentaram a emergência de uma etnicidade que, a partir do contato com outros grupos étnicos, demarcou fronteiras de afirmação, negociação e reconfiguração de identidades.

Segundo Woodward (2000, p. 8), as identidades "[...] adquirem sentido por meio da linguagem e dos sistemas simbólicos pelos quais elas são representadas". Em Santa Cruz do Sul, os imigrantes alemães e seus descendentes construíram e expressaram representações de identidades étnicas por meio de associações esportivas, fundadas a partir da década de 1860 , como as de tiro ao alvo e cavalaria.

Entre as décadas de 1860 e 1910, cerca de 40 sociedades de tiro ao alvo - denominadas

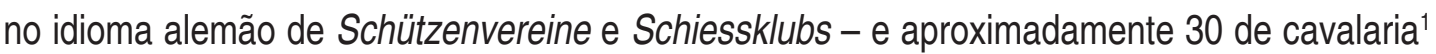
- com as nomeações de Kavallerieverein, Stechklubs, Ulanenverein - foram fundadas na localidade (ASSMANN, 2015; MAZO et al., 2012). Tais associações eram instituídas de forma semelhante, tanto no que se refere à organização interna, quanto ao planejamento e promoção de eventos. Além disso, ambas apropriavam-se de elementos associados a representações militares na sua conformação.

A presente pesquisa investiga como as associações esportivas de tiro ao alvo e cavalaria de Santa Cruz do Sul se configuraram em espaços de representações de identidades étnicas, entre o final do século XIX e começo do XX. O conceito de configuração será analisado a partir da definição de Norbert Elias (1980), que o compreende como um conjunto dinâmico de pessoas que se inter-relacionam, estabelecendo relações interdependentes e mutáveis.

A fim de responder ao problema de pesquisa, primeiramente, foi realizada uma revisão bibliográfica em livros, artigos, teses e dissertações a respeito do fenômeno estudado. 0 corpus documental da pesquisa foi composto por fontes impressas e reportagens coletadas no jornal Kolonie ${ }^{2}$ (1891-1941), de Santa Cruz do Sul. As reportagens estavam originalmente escritas em alemão e foram traduzidas para a língua portuguesa. Na sequência foi realizada a catalogação das informações extraídas dos jornais, a análise documental e o cotejamento.

Vale salientar que as fontes não são entendidas enquanto testemunhos diretos do passado, mas, sim, passíveis de alterações e intencionalidades, produzidas de determinado lugar (BARROS, 2012). Destarte, é necessário problematizar os documentos a partir do olhar crítico do pesquisador, interrogando, confrontando e triangulando as informações a todo 0 momento. Não se pretende, neste estudo, ratificar verdades absolutas, mas encontrar sinais do passado que remetam à verossimilhança do acontecido. Afinal, conforme afirma Pesavento (2008, p. 110), "[...] o resultado - a trama historiográfica construída - não é o real, mas uma

1 Prática realizada com o cavalo que consistia em acertar um alvo feito de couro com uma lança (KIPPER, Maria Hoppe. Sociedades de cavalaria em área de colonização alemã (Santa Cruz do Sul - RS). São Leopoldo, 1967. mimeog.).

2 No jornal Kolonie as informações sobre práticas esportivas estão situadas em diferentes sessões do jornal, sem local específico; encontramse, por exemplo, em seções textuais ou em anúncios. Os relatos sobre eventos esportivos no jornal Kolonie, geralmente, eram enviados ao jornal por correspondência. De tal modo, as notícias eram produzidas pelos próprios dirigentes das associações esportivas, mas nem sempre publicadas na íntegra. A decisão sobre o que e onde publicar ficava a cargo da direção do jornal. 
versão documentada e argumentada sobre o mesmo". A seguir, apresentamos uma versão dessa história, alcançada a partir da interpretação de vestígios deixados pelos homens do passado.

\section{IDENTIDADES TEUTO-BRASILEIRAS: UMA CONCEPÇÃO PLURAL}

A construção de uma identidade parte do reconhecimento do outro como diferente, estabelecendo fronteiras demarcadoras entre o nós e o eles, determinantes na identificação de um grupo étnico (BARTH, 1969). Estudos que abordam o desenvolvimento político, econômico e social de Santa Cruz do Sul definem as associações, para fins diversos, como recursos de afirmação de uma identidade étnica teuto-brasileira (NEUMANN, 2006; VOGT, 2006). Essa identidade estava associada a um passado em comum, a Heimat (pátria) Alemanha.

Importa ressaltar, entretanto, que não existia uma unidade alemã anterior à chegada dos imigrados ao sul do Brasil. A identidade, ou, melhor dizendo, as identidades dos imigrantes alemães, eram uma "[...] colcha de retalhos em que uma diversidade enorme de trajetórias se entrecruzava, movidas pelo estímulo da emigração" (WOORTMANN, 2000, p. 210). É provável que isto tenha desencadeado dificuldades de convivência entre os primeiros imigrantes que se dirigiram ao estado do Rio Grande do Sul.

Correa (2004, p. 35) afirma que "as identidades regionais dos imigrantes foram sendo negociadas e resultaram - por meio de interações intra e intergrupais - na formação de um grupo étnico alemão antes mesmo da unificação da Alemanha" em 1871. Houve, assim, um processo de "englobamento" de diferentes identidades em uma identidade teuto-brasileira, definida externamente por outros grupos que não compreendiam as diferenças culturais entre eles (WEBER; BOSEMBECKER, 2010). A despeito da classificação majoritária de imigrantes ou descendentes de alemães, também havia diferenças culturais - como o dialeto, 0 credo religioso, os hábitos - entre os moradores de Santa Cruz do Sul, que vieram de regiões diferentes da Alemanha3 ${ }^{3}$ VOGT, 2001).

A preocupação com a germanidade e a afirmação de limites étnicos "[...] praticamente inexistia no Brasil" nas primeiras décadas da imigração alemã (GANS, 2004, p. 114). Segundo Gans (2004, p. 114), "[...] os descendentes, contudo, seriam resgatados pelo pangermanismo no final do século XIX como membros da nação alemã". A nação era compreendida como uma comunidade de pertencimento herdada através de uma concepção de sangue, de povo alemão, e não enquanto Estado. A ligação ao Estado brasileiro era percebida a partir da cidadania.

A fim de legitimar uma identidade teuto-brasileira, um conjunto de representações foi apropriado pelos sujeitos identificados como tal. A língua alemã ${ }^{4}$, a religião e as associações são apontadas como elementos constituintes da identidade (NEUMANN, 2006). As associações esportivas são dotadas de sentidos atribuídos pelos sujeitos internos e externos a elas, atuando desta forma enquanto espaços de representação cultural de identidades (MAZO, 2003).

Em Santa Cruz do Sul, as associações voltadas para a prática do tiro ao alvo e cavalaria assumiram representações teuto-brasileiras. Afora a prática propriamente dita, tais sociedades serviam para o entretenimento, sociabilidade e compartilhamento de uma cultura

3 Os imigrantes que se instalaram em Santa Cruz do Sul procediam de regiões como Renânia, Pomerânia, Prússia Ocidental e Oriental, Silésia, Westfália, Brandenburgo (VOGT, 2001).

$4 \mathrm{Na}$ maioria das associações de tiro ao alvo e cavalaria, os documentos eram redigidos no idioma alemão (ASSMANN; MAZO, 2012). 
germânica. Além disso, buscavam a afirmação do grupo e de uma identidade teuto-brasileira por meio de símbolos, normas, comportamentos e outras formas de representações específicas (ASSMANN; MAZO, 2012).

Em muitas dessas entidades a língua alemã está registrada nas atas, estatutos, quadros comemorativos, pinturas em paredes, na própria denominação das associações. As primeiras associações esportivas de tiro e cavalaria ostentaram a representação "deutsch" (alemã) Deutscher Schützenverein ou Deutscher Kavallerieverein - já em sua designação. Na transição do século XIX para o XX, observamos uma nova configuração emergir: sociedades cuja denominação utilizava as expressões Deutscher-Brasilianischer ou Brasilianischer-Deutscher - que traduzidas significam, respectivamente, teuto-brasileiros ou brasileiro-teutos. Tais termos inferem uma afirmação de identidade étnica já no nome da sociedade.

As três associações de ulanos fundadas na região, também associações voltadas para a prática da cavalaria ${ }^{5}$ - a pioneira Ulanenklub Santa Cruz (1884), a Ulanenverein Rio Pardinho (1888) e a Ulanenverein de Ferraz (1892) -, entretanto, não utilizavam as expressões Deutscher-Brasilianischer ou Brasilianischer-Deutscher em seu nome. Mas o idioma alemão e seu uso também em documentos é destacado a todas essas ${ }^{6}$, bem como a criação de sentidos por meio de símbolos e discursos associados a representações de identidades culturais étnicas.

Asfronteiras delimitadas para legitimaro pertencimento a um grupo étnico teuto-brasileiro incluíam "[...] características culturais e sociais objetivamente identificáveis" (SEYFERTH, 1992, p. 2). Assim, festividades, desfiles, o idioma, a denominação da associação, a organização e as normas dos grupos permitiam a marcação de diferenças representativas. Um exemplo foi identificado em anúncio sobre a segunda festa dos atiradores do ano de 1894 promovida pela Sociedade de Atiradores Dona Josepha, que recebeu como convidada a associação da localidade de Linha Andreas. O pronunciamento inicial do comandante enaltecia o evento como momento de convivência social a ser compartilhado com "os irmãos do tiro": "nos encontramos aqui juntos hoje para coletivamente festejar mais uma festa alemã dos atiradores, para honrar o lema: alegria compartilhada é alegria em dobro." Tal afirmação evidencia o evento como um espaço de sociabilidade entre aqueles que se reconheciam como alemães e, também, como atiradores. Ainda, a publicação de tal anúncio pode remeter a uma intencionalidade de se fazer sentir e distinguir interna e externamente enquanto um "coletivo alemão". Neste caso, o tiro ao alvo é uma das práticas esportivas que identifica e produz identificação deste grupo perante aos demais. Todavia, isto não significa que os outros, isto é, aqueles que não pertenciam ao "coletivo alemão", não se apropriassem da prática do tiro e, posteriormente se inserissem em associações teuto-brasileiras ou até mesmo organizassem suas próprias associações de atiradores.

Segundo Ramos (2000), as festividades promovidas pelas associações se constituíam na expressão máxima da germanidade, sendo que tais ocasiões estavam inseridas no bojo de acontecimentos cuja origem estava na Alemanha unificada. As festas e competições nas associações de tiro ao alvo e cavaleiros são práticas culturais que produzem representações e identificação dentro e fora do grupo. Nas sociedades de atiradores e de cavaleiros as festas

5 As sociedades de ulanos se distinguiam das demais associações de cavalaria por aspectos "externos", ou seja, pelo uso de uniformes "mais vistosos e caros" e capacetes, semelhantes à Cavalaria Alemã, ostentados nos desfiles e festas (KIPPER, Maria Hoppe. Sociedades de cavalaria em área de colonização alemã (Santa Cruz do Sul - RS). São Leopoldo, 1967. mimeog., p. 25).

6 KIPPER, Maria Hoppe. Sociedades de cavalaria em área de colonização alemã (Santa Cruz do Sul - RS). São Leopoldo, 1967. mimeog. 7 DONA JOSEPHA. Kolonie, 30 maio 1894, p. 3. 
operavam como produtoras de imaginários, articulando discursos e imagens a fim de evocar uma memória social coletiva ${ }^{8}$.

Neste sentido, sobressaem as festividades em comemoração aos "heróis" alemães e os eventos em consagração à bandeira (Fahnenweihe). Uma solenidade em comemoração a Bismarck exemplifica tal apropriação, pois apresenta elementos de representação de uma identidade étnica construída a partir de uma concepção de germanidade, com referência a um passado comum. No evento, o salão do Clube União foi decorado com quadros de imperadores e príncipes alemães. Sobre o palco foi instalada uma coluna com as cores da Alemanha e, no seu topo, colocado o busto de Bismarck. À direita e à esquerda foram posicionadas as bandeiras das associações que participaram da comemoração. ${ }^{9}$

O discurso inicial foi proferido por Wilhelm Süffert que, segundo a publicação, "aclamou com entusiasmadas palavras o Império Alemão" e, ao final, "ressoou um entusiasmado "Bismarck hoch!'. As saudações ao imperador alemão prosseguem com uma canção elaborada especialmente para a ocasião, na qual Bismarck é ovacionado como "herói" e pessoa "idolatrada" pelo esforço despendido para a unificação do povo alemão. ${ }^{10}$ Após o discurso proferido em honra à "Vaterland", representada pela Alemanha, foram pronunciadas palavras saudando a Heimatland: o Brasil. ${ }^{11}$

Segundo Rambo (1994, p. 47-48), Heimatcompreende "[...] o espaço e o mundo comunal em que a pessoa nasce, cresce e se torna adulta e no qual se enraíza e com o qual desenvolve relações existenciais permanentes e indeléveis", podendo ser construída em qualquer parte do mundo desde que preservado o Deutschtum ${ }^{12}$ - sentimento de pertencimento étnico à pátria de origem (SEYFERTH, 1994) - e o idioma alemão. Tem como elemento definidor fundamental 0 princípio do jus sanguinis, a ideia de algo construído e herdado. A concepção Vaterland segue o mesmo princípio de Heimatland, sendo percebida enquanto realidade étnica e cultural, em que se vive como alemão e em que se fala como alemão. As expressões utilizadas no discurso proferido por Wilhelm Süffert sugerem que Vaterland refere-se à comunidade de pertencimento nacional, enquanto nação alemã, e a Heimatland indica a nova pátria onde se vive. Em outro texto, o Brasil é significado pela expressão "Adoptivvaterlandes Brasilien", ou seja, "pátria adotiva Brasil."13 A expressão Vater (pai) também remete à sociedade patriarcal e à concepção de descendência herdada, especialmente por via paterna.

A imagem de Bismarck assumia a representação do herói que é aclamado pela história comum da unificação dos estados alemães. Essa representação foi apropriada a fim de produzir um sentido de pertencimento ao grupo, uma identificação cultural e étnica. Tais concepções, no entanto, não são exclusivas das associações esportivas, mas são produzidas em uma relação dinâmica e interdependente com as redes que tecem a vida em sociedade. Faz-se a ressalva que essa e outras representações não apresentavam um consenso nem mesmo entre todos os teuto-brasileiros, ocorrendo conflitos entre aqueles que desejavam

8015 de novembro, dia de aniversário da República, também era comemorado por associações esportivas (CONVITE. Kolonie, Santa Cruz do Sul, 14 nov. 1894). Em 1897, as sociedades de atiradores, ginástica e ulanos, oriundas da Vila de Santa Cruz, participaram das homenagens ao presidente do estado do Rio Grande do Sul Julio de Castilhos (A HOMENAGEM. Programa de homenagem a Júlio Prates de Castilhos. Santa Cruz, 3 jun. 1897).

9 Participaram da comemoração a Deutsche Schützenverein, a Lidertafel, a Turnverein e o Musterreiter, respectivamente, associações voltadas à prática do tiro, do canto, da ginástica e os caixeiros viajantes (DIE BISMARCK-FEIER. Kolonie, Santa Cruz do Sul, 3 abr. 1895).

10 DIE BISMARCK-FEIER. Kolonie, Santa Cruz do Sul, 3 abr. 1895.

11 DIE BISMARCK-FEIER. Kolonie, Santa Cruz do Sul, 3 abr. 1895.

12 Para René Gertz (2008, p. 132), o Deutschtum "existia como ideologia e como prática na construção, sobretudo, de instituições". 13 FIRMBACH, Theodor. Die deutsche Rede am 15 november. Kolonie, Santa Cruz do Sul, 17 nov. 1894. 
afirmar seus costumes e práticas e outros que defendiam, por exemplo, a apropriação da língua portuguesa nas associações.

Nos eventos de consagração à bandeira (Fahnenweihe), representações de identidades culturais teuto-brasileiras eram afirmadas. Nestas comemorações, a bandeira era apropriada enquanto "nobre" representação de associações esportivas, seu significado era enaltecido e rememorado como "um símbolo da essência da camaradagem, da lealdade alemã e da união"14. Ainda, o caráter militar e a história construída da colonização eram ressaltados a partir da bandeira como meio de demarcação de uma identidade étnica. ${ }^{15}$

A bandeira de cada associação de cavalaria tinha características próprias e se diferenciava das bandeiras de outras associações. Segundo Kipper ${ }^{16}$, "[...] tinham invariavelmente um lado com as côres da Alemanha (preto, branco e vermelho), e o outro lado com as cores brasileiras (verde e amarelo)". A dupla identificação - teuto-brasileiro - ficaria, então, evidenciada também na bandeira de sociedades de cavalaria.

Todavia, na descrição da bandeira da Deutsch-brasilianische Kavallerie-Club da localidade de Picada Velha (Linha Santa Cruz), em publicação ${ }^{17}$ que trata do sétimo aniversário da associação, nota-se características diferenciadas. De um lado, ao invés da Alemanha, as cores remetem à "bandeira prussiana, preto e branco, com o brasão da sociedade: Disco de anéis [alvo], lanças, chicote e ferradura, circundado por um coroa de folhas de café", e do outro lado a identificação não é com a bandeira brasileira, mas sim "mostra-se as cores do Rio Grande do Sul verde, vermelho e amarelo e trás escrito: 'Clube Teuto-brasileiro de Cavalaria, Picada Santa Cruz, 1896."'18 A despeito da marcação teuto-brasileira (deutsch-brasilianischer) na denominação da associação esportiva, a bandeira trazia representações prussianas e sulrio-grandenses, estabelecendo uma dualidade prússio-sul-rio-grandense, ou uma identificação teuto-brasileira localizada. De tal modo consideravam-se prussianos além de alemães, bem como sul-rio-grandenses além de brasileiros.

Cabe ressaltar que o Império Alemão foi criado em 1871 e a Prússia, estado alemão de forte base econômica e política, liderou o movimento de unificação dos estados alemães. Bismarck, figura que representa este processo, era prussiano. Deste modo, demarcar uma identidade prussiana poderia ser uma forma de representar uma marcação étnica simbólica ainda mais associada aos ideais do germanismo.

A afirmação enquanto sul-rio-grandenses é marcada também na denominação de associações como o Riograndenser Damenschiessklub (Clube de Tiro de Damas Riograndense), fundado em 1900 na Vila de Santa Cruz, o Riograndenser Cavallerie-Club (Clube de Cavaleiros Riograndense), fundado em 1902 ou 1903 na localidade de Sinimbu. Desta forma, podemos inferir que estas associações congregavam representações culturais teuto-sul-rio-grandeses, pois se afirmavam cidadãos do Rio Grande do Sul na denominação do seu grupo, em espaços voltados para práticas esportivas vinculadas a uma tradição alemã, como o tiro e a cavalaria. $A$

140 texto, enviado por correspondência pela própria associação, relata uma festividade em homenagem à bandeira da Schützenverein Villa Thereza, que também congregou as associações de atiradores da localidade de Villa Thereza e a Sociedade de Atiradores Santa Cruz (KORRESPONDENZ. Kolonie, Santa Cruz do Sul, 23 maio 1891). Outra publicação que faz referências semelhantes corresponde a uma festividade da Ulanenverein Riopardinho (RIOPARDINHO. Kolonie, Santa Cruz do Sul, 21 fev. 1903).

15 RIOPARDINHO. Kolonie, Santa Cruz do Sul, 21 fev. 1903; KORRESPONDENZ. Kolonie, Santa Cruz do Sul, 23 maio 1891.

16 KIPPER, Maria Hoppe. Sociedades de cavalaria em área de colonização alemã (Santa Cruz do Sul - RS). São Leopoldo, 1967. p. 32. mimeog. 
adoção de uma representação de identidade cultural - alemã, teuto-brasileira, sul-rio-grandense - na denominação da associação, definindo e diferenciando o pertencimento a determinado grupo, agrega sentidos a estes coletivos tanto interna quanto externamente.

Outra associação que se distinguiu das demais foi a Cavalaria União, fundada em 1885, cuja comunicação no cotidiano era em língua portuguesa, ${ }^{19}$ enquanto na maioria predominava o idioma alemão. Para Krebs, a Cavalaria União congregava um grupo de Hussardos ${ }^{20}$. Esta "tropa", como alude o autor ${ }^{21}$, existiu na Picada Velha (hoje Linha Santa Cruz) na transição do século XIX para o século XX, sendo semelhante aos ulanos em organização e finalidade. A explicação para tal semelhança, de acordo com Krebs²2, está respaldada nas principais personalidades da associação de ulanos, os Werlang, soldados brasileiros veteranos da Guerra do Paraguai (1864-1870) ${ }^{23}$. Kipper ${ }^{24}$ corrobora Krebs ${ }^{25}$ e acrescenta a descrição dos uniformes usados pelos Hussardos: calça branca com friso na cor vermelha nas laterais, túnica escura com enfeites vermelhos e "quepe napoleônico", semelhante aos adotados pelos brasileiros na Guerra do Paraguai.

A distinção pelo idioma pode, também, estar associada às dinâmicas sociais que permeavam o final do século XIX no Brasil. A Proclamação da República (1889) e a Constituição de 1891 ampliaram os direitos dos imigrantes e descendentes de intervir no processo político através do voto (KRAUSE, 2002), ou seja, ampliaram as possibilidades de reconhecimento e afirmação enquanto cidadãos brasileiros.

Além disso, no período de transição do século XIX para o século XX, santa-cruzenses ascendiam economicamente e casas comerciais e pequenas indústrias eram estabelecidas, propiciando o contato com grupos de outras etnias. As necessidades comerciais impeliam a interação com luso-brasileiros, por exemplo, e o imperativo de aprender a língua do país também aumentava. No início da década de 1890 percebemos, então, uma nova exigência que se configurava na comunidade local, associado à representação identitária "ser brasileiro": o saber falar português.

\section{IDENTIDADES EM NEGOCIAÇÃO: APROXIMAÇÕES E DISTANCIAMENTOS}

Logo após a Proclamação da República (1889), a Lehrerverein (sociedades de professores) publicou no Kolonie sua proposta para o novo ano escolar em Santa Cruz do Sul. ${ }^{26}$ Dentre as onze cláusulas, a décima chama atenção, pois sugere que em todas as escolas da colônia haja períodos dedicados às aulas na língua "brasileira"27. No mês seguinte à divulgação da proposta, em fevereiro de 1892, a Lehrerverein realizou uma conferência a respeito da inclusão da língua portuguesa nas escolas alemãs. ${ }^{28}$

\footnotetext{
19 KIPPER, Maria Hoppe. Sociedades de cavalaria em área de colonização alemã (Santa Cruz do Sul - RS). São Leopoldo, 1967. mimeog. 20 Hussardo era um "soldado de cavalaria ligeira, criado pelo exército húngaro e logo imitado em muitas nações europeias", como a Alemanha. (KREBS, Carlos Galvão. Ulanos no Brasil. Revista do Globo, p. 31-33, 28 abr. 1951. p. 33).

21 KREBS, Carlos Galvão. Ulanos no Brasil. Revista do Globo, p. 31-33, 28 abr. 1951.

22 KREBS, Carlos Galvão. Ulanos no Brasil. Revista do Globo, p. 31-33, 28 abr. 1951.

23 Conflito armado entre o Paraguai e a Tríplice Aliança, formada pelo Brasil, Argentina e Uruguai.

24 KIPPER, Maria Hoppe. Sociedades de cavalaria em área de colonização alemã (Santa Cruz do Sul - RS). São Leopoldo, 1967. mimeog. 25 KREBS, Carlos Galvão. Ulanos no Brasil. Revista do Globo, p. 31-33, 28 abr. 1951.

26 SCHULANGELEGENHEITEN. Kolonie, Santa Cruz do Sul, 2 jan. 1892.

27 Além disso, o primeiro parágrafo sugere a implantação de educação compulsória por quatros anos para crianças na faixa etária entre sete e onze anos ou entre oito e doze anos (SCHULANGELEGENHEITEN, 2 jan. 1892).

28 LEHRERVEREIN. Kolonie, Santa Cruz do Sul, 13 abr. 1892.
} 
Tais informações indicam que existia uma preocupação por parte da instituição de ensino local em educar os descendentes de imigrantes alemães na língua do país. As sugestões da Lehrerverein foram atendidas, pois em junho do mesmo ano, dentre sete concorrentes à função de professores da colônia - todos com sobrenomes alemães -, um foi dispensado por reprovação na prova de língua portuguesa e outros dois se mostraram chocados com a exigência, sendo que um deles não compareceu à realização da prova. ${ }^{29}$

O aprendizado da língua portuguesa também se torna preocupação de pessoas ligadas ao comércio: "homem de negócios está procurando um professor privado, que fala e ensina alemão e português". ${ }^{30}$ Além disso, encontrou-se 0 anúncio de aulas de português à noite para pessoas adultas. ${ }^{31} \mathrm{~A}$ exigência de falar português torna-se proeminente, pois significava ter 0 direito ao voto, ou seja, ser reconhecido como cidadão brasileiro. ${ }^{32}$

Na mesma época, uma abertura no sentido de relacionar-se com "brasileiros" desponta no associativismo esportivo, por meio de um anúncio e convite para o terceiro Bundesschiessen (Torneio de Tiro da Federação), que aconteceria em Santa Maria, "no qual os atiradores brasileiros devem se juntar e se ia ganhar novos simpatizantes e adeptos à essência de atirador". ${ }^{33}$ Entretanto, a divulgação foi redigida na língua alemã, delimitando a participação daqueles que não compreendiam o idioma. A ausência de tal preocupação pode sugerir ambiguidades e interesses velados nesta tentativa de "abertura" ao diferente.

Além desses, outros indícios apontam para uma inclinação em assegurar representações de uma cultura identificada como brasileira ${ }^{34}$, associada à nova Heimat, como, por exemplo, as comemorações de acontecimentos históricos relacionados ao Brasil, ao Rio Grande do Sul e ao município de Santa Cruz do Sul. As festividades, no entanto, surgem de forma pontual e se modificam quanto à organização das comemorações. $O$ descobrimento da América, por exemplo, foi festejado em um evento "cheio de vida" por 15 associações da região (DAS COLUMBUSFEST, 15.10.1892). ${ }^{35}$ Após o desfile das sociedades pela localidade, os Srs. Hermsdorf e Azevedo, respectivamente, proferiram os discursos em alemão e português. Desta forma, inferimos que o evento contou com a presença de pessoas que compreendiam um ou outro idioma, evidenciando certa interação entre diferentes grupos étnicos. Segundo o jornal (DAS COLUMBUSFEST, 15.10.1892), 500 pessoas participaram do dia festivo, sugerindo um número expressivo para a comunidade. A manifestação sobre a vivacidade do evento e a somatória de participantes podem, também, revelar uma construção de um propósito: ressaltar, publicamente, a importância da comemoração para aquele grupo.

Se por um viés a adoção da língua portuguesa era enaltecida no início da década de 1892, a preservação da língua alemã, chamada de Muttersprache, é evocada anos mais tarde. Isto ratifica uma relação dinâmica e fluida nas formas de representar a realidade. Uma história não linear, mas que atua em configurações dinâmicas em que as forças sociais são "exercidas pelas pessoas, sobre outras pessoas e sobre elas próprias" (ELIAS, 1980, p. 17).

29 EXAMEN. Kolonie, Santa Cruz do Sul, 25 jun. 1892.

30 EIN PRIVATLEHRER. Kolonie, Santa Cruz do Sul, 16 jan. 1892. Encontrado no Centro de Documentação da UNISC.

31 ABENDSCHULE für Erwazchsene. Kolonie, Santa Cruz do Sul, 8 out. 1892.

32 QUALIFIKATION. Kolonie, Santa Cruz do Sul, 15 out. 1892

33 VOM 6. BIS zum 10. November. Kolonie, Santa Cruz do Sul, 13 ago. 1892.

34 A construção de uma identidade brasileira envolvia a busca por um Estado unificado e uma cultura em comum. Este desafio, conforme Fiorin (2009) foi um dos problemas que intelectuais brasileiros tentaram resolver no fim do século XIX. Segundo este autor (FIORIN, 2009, p. 18), no que diz respeito à dimensão cultural, buscavam-se elementos da "existência e características da brasilidade", embora soubessem da heterogeneidade de traços culturais dos múltiplos grupos étnicos que conviviam no país. No campo do associativismo esportivo sul-riograndense, o estudo de Mazo (2003) aborda as disputas identitárias entre os "clubes de alemães", "clubes de italianos" e "clubes de brasileiros". 35 DAS COLUMBUSFEST. Kolonie, Santa Cruz do Sul, 15 out. 1892. Encontrado no Centro de Documentação da UNISC. 
Para o governo alemão, os núcleos coloniais com ascendentes alemães, como 0 caso de Santa Cruz do Sul, eram oportunidades de expandir seu mercado. O Deutschtum, reconhecido como importante aliado neste processo, foi estimulado nessas regiões pelo Estado alemão, inclusive destinando auxílio às associações recreativas e culturais, bem como filiando essas sociedades alemãs no estrangeiro (VOGT, 2001).

Segundo Magalhães (1993, p. 3), à Liga Pangermânica ${ }^{36}$ pode ser atribuída a responsabilidade de transmitir considerável número de iniciativas para a "difusão do ideário nacionalista alemão". Aliadas a isso, as concepções que pairavam sobre um "perigo alemão" reforçavam o sentimento de "ser estrangeiro" no país. A divulgação de tais concepções, bem como a aproximação entre a Alemanha e o Brasil, era facilitada com o auxílio de periódicos voltados a essa população em território brasileiro (MAGALHÃES, 1993).

No jornal Kolonie, especialmente no período de transição do século XIX para $\circ \mathrm{XX}$, circulavam discursos pangermanistas. Um texto publicado pelo Kolonie, que tratava da comparação entre o Brasil e a América do Norte, lamentou a utilização do idioma português nas "casas de famílias alemãs". O texto é finalizado com a seguinte frase: "Ihr deutschen Landsleute, bewahrt euch eure Muttersprache" (vocês compatriotas alemães, preservem a sua língua mãe). ${ }^{37} \mathrm{~A}$ manutenção da língua materna em território brasileiro estava relacionada com a preservação do Deutschtum e a manutenção do ideal da nacionalidade alemã.

Ao noticiar, em 1900, a comemoração do aniversário do Imperador alemão Wilhelm II (Imperador da Alemanha no período de 1888 e 1918) ${ }^{38}$, o Kolonie apresenta elementos que corroboram as afirmações de Magalhães (1993). Segundo o jornal, os grupos locais da Liga Pangermânica de Santa Cruz (Alldeustcher Verband) se encontraram na sociedade de canto Lidertafel para uma festa. "O jardim estava ricamente enfeitado de lampiões, bem como uma bandeira alemã circundada de medalhões do Imperador. Em cima brilha tão transparente 0 lema da Liga Pangermânica: 'Lembra-te de que tu és um alemão'”. ${ }^{9}$

O início dos festejos foi realizado pela sociedade Lidertafel, cujos membros cantaram "Wacht am Rhein" (Guarda do Reno). Esta canção surgiu em um contexto de resistência em oposição à ocupação napoleônica, "período marcante para o surgimento de um sentimento de pertença alemã" (GANS, 2004, p. 182). Isto reforça a ideia de restaurar uma herança alemã elaborada pelo movimento pangermanista a fim de produzir sentidos de pertença a uma comunidade alemã imaginária.

Na sequência, Schlegkendal, diretor da Lidertafel, proferiu um discurso exaltando o Imperador Wilhelm e a "poderosa" Alldeutschland (Pan-Alemanha): "que os seus braços se estendem sobre os oceanos e por todo lado marca o nome alemão [sic]". No seguimento da comemoração, ainda houve o segundo discurso oficial, pronunciado por Carlos $\operatorname{Trein}^{40}$, que falou a respeito do Deutschtum..$^{41}$ Ainda, em seu discurso proferiu uma

\footnotetext{
36 Foi criada em 1891 com a finalidade de fomentar a política colonial do império alemão e ampliar o espaço territorial do povo alemão, investindo na propagação de um forte sentimento nacionalista nos "alemães do exterior" (MAGALHÃES, 1993). Para Seyferth (1994, p. 20) o pangermanismo atuava como divulgador "de uma doutrina de superioridade racial teutônica".

37 DIE DEUTSCHE Sprache. Kolonie, Santa Cruz do Sul, 9 jan. 1901.

38 Em 1872, houve a comemoração do aniversário de Wilhelm I em Porto Alegre (GANS, 2004).

39 DIE GEBURTSTAGFEIER C. M. des deutschen Kaiser. Kolonie, Santa Cruz do Sul, 31 jan. 1900.

40 Foi presidente do Clube União; era maçom; líder do Partido Federalista; se dedicou à Igreja Evangélica; fez parte da diretoria do Colégio Sinodal (atual Colégio Mauá); fundador e primeiro presidente do jornal Kolonie (KRAUSE, 2002; NORONHA, 2012). Em Porto Alegre foi segundo diretor da Radfahrer Verein Blitz (Sociedade Ciclística Relâmpago) em 1897.

41 DIE GEBURTSTAGFEIER C. M. des deutschen Kaiser. Kolonie, Santa Cruz do Sul, 31 jan. 1900.
} 
mensagem aos luso-brasileiros: "não mais com invejosos e rancorosos olhares, mas com total admiração e agradecimento precisam reconhecer, que nós imigrantes alemães nos tornamos indispensáveis valiosos cidadãos desse novo país [...]" ${ }^{42}$

Como fica evidente no discurso propagado pelo jornal, Carlos Trein defendia uma posição cultural e étnica teuto-brasileira, associada à etnicidade alemã, através do Deutschtum e de limites como o trabalho alemão, bem como à condição de brasileiros enquanto cidadãos da nova pátria. Ainda afirma uma relação de superioridade e a marcação da diferença entre o "nós" e o "eles", na figura dos luso-brasileiros, que apesar de "concidadãos", também "invejavam" a laboriosidade teuto-brasileira. Segundo Gans (2004, p. 198), a laboriosidade "é uma categoria relevante do próprio sistema cultural de referência", sendo o discurso da qualidade do trabalho alemão uma forma de reverter "toda uma condição de desqualificação social que existia anteriormente" e afirmar uma identidade cultural e étnica.

Carlos Trein assumia uma posição de liderança étnica no contexto santa-cruzense do período de transição do século XIX para o século XX, pois tinha "papel tanto na formulação simbólica do grupo quanto na defesa de interesses e direitos" (WEBER, 2014, p. 714). Conforme Noronha (2012, p. 88), Carlos Trein era "sem dúvida, uma das figuras de maior influência política, cultural e econômica na comunidade" de Santa Cruz do Sul. Para Weber (2014, p. 704), "[...] a presença de "líderes" pode ser muito significativa na existência dos grupos sociais, particularmente em termos da visibilidade, identidade e, sobretudo, do poder de atuação destes grupos".

Na condição de presidente do jornal Kolonie, Carlos Trein provavelmente contribuiu para a veiculação de notícias acerca de uma concepção de nação alemã. Associações esportivas também agenciaram e difundiram esta concepção, como mostra uma notícia do Kolonie, escrita a partir de uma publicação do $D$. Volksblatt, que anotava a convocação da Schützenbund (Federação de Atiradores), localizada em Porto Alegre, às sociedades de atiradores do estado - tanto as associadas quanto as não sócias da entidade - para participarem da assembleia geral. No texto, a Federação de Atiradores faz um apelo para que as associações que ainda não são federadas façam a sua filiação, reforçando o chamado para as sociedades da colônia: "[...] todos os irmãos atiradores devem se manter juntos para preservação e cultivo da boa arte alemã do atirador". ${ }^{43}$

A partir da união das Schützenvereine do Rio Grande do Sul, a Federação de Atiradores expressa seu desejo de formar "uma unidade com as grandes federações de atiradores alemãs da Alemanha, da Áustria, da Suíça e dos Estados Unidos da América" e reforça, ao final: "novos progressos e ninguém fica para trás!". ${ }^{44}$ Em outras palavras, são vistos como alemães todos aqueles que preservam a língua e a cultura alemã - como a prática do tiro ao alvo independente de onde estejam estabelecidos. Essa concepção remete à ideia de estado-nação transnacional, associado à descendência comum (SCHILLER; FOURON, 1997).

Tal condição é reiterada em um texto publicado em agosto de 1914 no Kolonie, logo após o início do conflito da Primeira Guerra Mundial. Nesta publicação, a Schützenbund für Rio Grande do Sul (Federação de Atiradores do Rio Grande do Sul) faz um chamado para as Schützenvereine (sociedades de atiradores) do estado solicitando auxílio financeiro na forma de

42 DIE GEBURTSTAGFEIER C. M. des deutschen Kaiser. Kolonie, Santa Cruz do Sul, 31 jan. 1900. 43 EIN MAHNWORT na unsere deutschen Schützenverein. Kolonie, Santa Cruz do Sul, 29 jun. 1904. 
doações para as "necessidades da guerra" (Kriegsnot-Spende)..$^{45} \mathrm{~A}$ Deutscher Schützenverein Santa Cruz adere ao chamado com a promoção de um Preisschiessen (Tiro a prêmio) a fim de angariar fundos. ${ }^{46}$

A Federação de Atiradores do Rio Grande do Sul se refere aos habitantes da Alemanha como "nosso povo de origem", "companheiros de origem", "irmãos alemães". Essas expressões, associadas à preocupação evidente no texto com a preservação do Deutschtum, reforçam a concepção de identidade cultural étnica construída historicamente e culturalmente por uma retórica de sangue comum e de passado comum. Segundo o texto "o destino do povo alemão, e com isso o destino do Deutschtum em toda a terra, será decidido nessa semana sobre 0 campo de batalha e nas águas europeias". A guerra que iniciava visava, para os dirigentes da Schützenbund, à permanência do "Império alemão único", conquistado em 1870 e relembrado no texto, e à "conservação do nosso Volkstum como um importante fator de influência na história do mundo." 4748

Tal postura, juntamente com as representações paramilitares, provavelmente, contribuiu para o enfraquecimento social das associações de atiradores e cavaleiros no período que perdurou a Primeira Guerra Mundial, especialmente após a entrada do Brasil no conflito. No jornal Kolonie, no decorrer dos anos até o seu fechamento, em 1917, encontramos uma grande e progressiva redução no número de anúncios dessas sociedades. 0 desvanecer dos atiradores e cavaleiros da janela social e as ações de abrasileiramento impostas pelo governo certamente provocaram instabilidades e mudanças, pelo menos naquele período, quanto às representações de identidades étnicas configuradas por estes grupos.

\section{CONSIDERAÇÕES FINAIS}

Neste estudo, compreendemos as identidades negociadas pelas associações de atiradores e cavaleiros como um processo plural e dinâmico. As práticas esportivas dessas associações, no período demarcado no estudo, foram apreendidas como práticas culturais inseridas em determinado contexto, no qual experimentaram rupturas e continuidades. Eram negociadas em um espaço alterado pelas relações dinâmicas, as quais fluem no decorrer do tempo e do espaço.

No final do século XIX, coligadas aos novos discursos do Brasil República e às configurações sociais vigentes no período, as associações buscaram produzir e manifestar representações de identidades étnico-culturais teuto-brasileiras. Isto é indicado, especialmente, na denominação das associações, nas celebrações à bandeira e nos discursos reproduzidos pela imprensa local. A busca por referência a um passado comum, associado à nação alemã, é encontrada na construção e exaltação de um herói da pátria. Ainda, podemos perceber que a expressão "Deutsch-Brasilianischer" - ou teuto-brasileiro - apareceu de forma recorrente na denominação de sociedades e clubes esportivos nos anos finais do século XIX.

Salienta-se que, se em determinados momentos foram observadas intenções de aproximação com representações identitárias "brasileiras", em outros manifestaram-se

45 SCHÜTZENBUND für Rio Grande do Sul. An die Schützen. Kolonie, Santa Cruz do Sul, 26 ago. 1914.

46 DEUTSCHER Schützenverein S. Cruz. Kolonie, Santa Cruz do Sul, 28 ago. 1914.

47 A expressão Volkstum - entrelaçada à noção de Deutschtum - pode ser definida pelo conjunto de particularidades de uma nação alemã, como a língua e a cultura (GANS, 2004).

48 SCHÜTZENBUND für Rio Grande do Sul. An die Schützen. Kolonie, Santa Cruz do Sul, 26 ago. 1914. 
interesses de distanciamento, seja pela afirmação de diferenças através do idioma alemão, da prática esportiva ou da união em associações. Os discursos interpretados neste estudo suscitam a percepção de um processo complexo e embaraçado; uma história que não é construída sem choques ou confrontações, mas, sim, nas trocas que são produzidas deste emaranhado de pessoas diferentes.

Ainda que apareça de forma reincidente, a designação "teuto-brasileiro" não deve ser compreendida enquanto uma produção identitária no singular. Tampouco compreende-se como a união de dois povos distintos em uma única entidade. Mas, sim, como pessoas que se aproximam e se distanciam de representações culturais identitárias atribuídas a modos de vida em diferentes contextos, se apropriando e remanejando tais representações para construir sentidos de pertencimento. Sugere-se, assim, pensar o termo na sua forma gramatical plural, ou seja, como identidades teuto-brasileiras.

Fazemos a ressalva que, apesar da utilização significativa do jornal Kolonie como fonte de pesquisa, compreendemos que os discursos veiculados apreendiam uma representação social da realidade. Isto não significa que outras representações não fossem apropriadas de formas diferentes ou ressignificadas em outras instâncias. Neste estudo, apresentamos, por meio da interpretação dos rastros deixados pelos agentes do passado, uma versão da história do fenômeno do associativismo esportivo em Santa Cruz do Sul. No entanto, sugere-se que estudos futuros sejam desenvolvidos por meio da análise de outras fontes de pesquisa.

\section{REFERÊNCIAS}

ASSMANN, Alice Beatriz. 0 associativismo esportivo em Santa Cruz do Sul/Rio Grande do Sul: configurações de práticas culturais (da década de 1880 à década de 1910). 2015. 154 f. Dissertação (Mestrado em Ciências do Movimento Humano) - Escola de Educação Física, Fisioterapia e Dança, Universidade Federal do Rio Grande do Sul, Porto Alegre, 2015.

ASSMANN, Alice Beatriz; MAZO, Janice Zarpellon. AS SCHÜTZENVEREINE: Sociedades de Atiradores - de Santa Cruz do Sul: um tiro certo na história do esporte no Rio Grande do Sul. Esporte e Sociedade, v. 7, n. 20, p. 122-153, set. 2012.

BARROS, José D’Assunção. A fonte histórica e seu lugar de produção. Cadernos de Pesquisa CDHIS, v. 25, n. 2, p. 407-429, jul./dez. 2012.

BARTH, Fredrik. Introduction. In: BARTH, Fredrik. Ethnic Groups and Boundaries. Boston: Little Brown, 1969. p. 9-38.

CORREA, Sílvio Marcus de Souza. Identidade Alemã e Alteridade no Rio Grande do Sul. In: CUNHA, J. L.(Org.). Cultura Alemã 180 anos: 1824-2004. Porto Alegre: Nova Prova, 2004. p. 31-44.

ELIAS, Norbert. Introdução à Sociologia. Lisboa: Edições 70, 1980.

FIORIN, José Luiz. A construção da identidade nacional brasileira. Bakhtiniana, v. 1, n. 1, p. 115-126, 2009. 
GANS, Magda Roswita. Presença Teuta em Porto Alegre no Século XIX: 1850 - 1889. Porto Alegre: Editora UFRGS, 2004.

GERTZ, René. Brasil e Alemanha: os brasileiros de origem alemã na construção de uma parceria histórica. Textos de História, v. 16, n. 2, p. 119-149, 2008.

KRAUSE, Silvana. Migrantes do Tempo: vida econômica, política e religiosa de uma comunidade de imigrantes alemães na República Velha. Santa Cruz do Sul: EDUNISC, 2002.

MAGALHÃES, Marionilde Dias Brebpohl. Alemanha, mãe-pátria distante: uma utopia pangermanista no sul do Brasil. 1993. 320f. Tese (Doutorado) - Instituto de Filosofia e Ciências Humanas, Universidade Estadual de Campinas, Campinas, 1993.

MAZO, Janice Zarpellon et al. Associações Esportivas do Rio Grande do Sul (1867-2009): lugares e memórias. Novo Hamburgo, RS: Editora da FEEVALE, 2012. 1 CD-ROM.

MAZO, Janice Zarpellon. Emergência e a Expansão do Associativismo Desportivo em Porto Alegre (1867-1945): espaço de representação da identidade cultural teuto-brasileira. 2003. $254 f$. Tese (Doutorado) - Faculdade de Educação Física e Ciências do Desporto, Universidade do Porto, Portugal, 2003.

NEUMANN, Marinês Teresinha. Narrativas identitárias e associativismo de tradição germânica na região de Santa Cruz do Sul: o discurso da identidade regional (1850-1950). Santa Cruz do Sul: EDUNISC, 2006.

NORONHA, Andrius Estevam. Beneméritos empresários: história social de uma elite de origem imigrante do sul do Brasil (Santa Cruz do Sul, 1905-1966). 2012. 370 f. Tese (Doutorado em História) - Faculdade de Filosofia e Ciências Humanas, Pontifícia Universidade Católica do Rio Grande do Sul, Porto Alegre, 2012.

PESAVENTO, Sandra Jatahy. O mundo da imagem: território da história cultural. In: PESAVENTO, Sandra Jatahy; SANTOS, Nadia Maria; ROSSINI, Miriam de Souza (Org.). Narrativas, imagens e práticas sociais: percursos em história cultural. Porto Alegre: Asterisco, 2008. p. 99-122.

RAMBO, Arthur Blásio. Nacionalidade e cidadania. In: MAUCH, Cláudia; VASCONCELLOS, Naira. Os Alemães no sul do Brasil: cultura, etnicidade, história. Canoas: Ulbra, 1994. p. $43-53$.

RAMOS, Eloísa. 0 teatro da sociabilidade: os clubes sociais como espaço de representação das elites urbanas alemãs e teuto-brasileiras - São Leopoldo 1858-1930. 2000. 150f. Tese (Doutorado em História) - Universidade Federal do Rio Grande do Sul, Porto Alegre, 2000.

SCHILLER, Nina Glick; FOURON, Georges. "Laços de sangue»: os fundamentos raciais do estado-nação transnacional. Revista Crítica de Ciências Sociais, n. 48, p. 33-66, 1997.

SEYFERTH, Giralda. A identidade teuto-brasileira numa perspectiva histórica. In: $\mathrm{MAUCH}$, Cláudia; VASCONCELLOS, Naira. Os Alemães no sul do Brasil: cultura, etnicidade, história. Canoas: Ulbra, 1992. p. 11-27.

SEYFERTH, Giralda. As identidades dos imigrantes e o melting pot nacional. Horizontes Antropológicos, v. 14, p. 143-176, 2000.

SEYFERTH, Giralda. Etnicidade e cultura: a constituição da identidade teuto-brasileira. In: ZARUR, George de Cerqueira Leite (Org.). Etnia y Nación en América Latina. Washington, D.C. : Organization of American States, 1994-1996. v. 2, p. 1-10. 
VOGT, Olgário Paulo. Imperialismo: a face oculta do germanismo. Ágora, v. 7, n. 2, p. 49-92, jul./dez. 2001.

VOGT, Olgário Paulo. A colonização alemã no Rio Grande do Sul e o capital social. 2006. 230f. Tese (Doutorado em Desenvolvimento Regional) - Universidade de Santa Cruz do Sul, Santa Cruz do Sul, 2006.

WEBER, Regina. Líderes, intelectuais e agentes étnicos: significados e interpretações.

Diálogos, v. 18, n. 2, p. 703-733, maio/ago. 2014.

WEBER, Regina; BOSEMBECKER, Patrícia. Disputas pela memória em São Lourenço do Sul: uma visão histórica de representações étnicas. Cadernos do CEOM (UNOESC), v. 23, p. 347369, 2010.

WOODWARD, Kathryn. Identidade e diferença: uma introdução teórica e conceitual. In: SILVA, Tomaz Tadeu. Identidade e diferença: a perspectiva dos estudos culturais. Petrópolis: Vozes, 2000. p. 7-72.

WOORTMANN, Ellen Fensterseifer. Identidades e memória entre teuto-brasileiros: os dois lados do Atlântico. Horizontes Antropológicos, v. 6, n. 14, p. 205-238, nov. 2000. 